\title{
A People-Centered Economy
}

\author{
Innovation for Jobs (i4j.info) recently published \\ a book ${ }^{\mathrm{a}}$ describing a new, people-centered \\ view of work. In some ways, this is a kind of \\ revolutionary Copernican view of work.
}

Rather than organizing work around tasks, the idea is to organize work around people and their skills. One thesis of this book is that organizing work around tasks leads companies to focus on reducing the cost of tasks by increasing productivity, reducing the need for people to do work. Automation and robotics derive their attraction in part from this incentive. An alternative view seeks to increase the value of people by maximizing their utility and shaping work/jobs around their strengths. I have written before about strengths and noted, in particular, the Gallup Corporation's StrengthsFinder application $^{\mathrm{b}}$ that helps people discover and rank-order the skills and capabilities they have.

As we ponder the future of work, it is important to recognize how essential work is to global socioeconomic conditions and how important it is to the individuals who perform it. In a world in which money is the primary medium of exchange, payment for work is essential. The authors of The People Centered Economy recognize that much effort has gone into encouraging people to spend more (think advertising), but not so much into helping people earn more (that is, to make themselves more valuable). Meaningful work is fulfilling and payment for it enables people

\footnotetext{
a The People Centered Economy; The New Ecosystem for Work. IIIJ Foundation, 2018, ISBN 1729145922

b https://www.gallupstrengthscenter.com/home/ en-us/benefits-of-cliftonstrengths-34-vs-top-5
}

to support their families and participate in the economy.

In capitalist societies, there is typically a distinction made between owners and workers. The owners participate in the value of the company while the workers are paid to work. This distinction creates a disparity between these two cohorts, particularly in the case of successful companies. With relatively few exceptions, the workers do not participate in the value of the company except to the extent they are paid for their work. Stockholders (that is, owners) participate in the value of the company. Gallup is an exception, for example, because the company is owned by its employees who participate in the value of the company as well as being paid for their work. Without the efforts of the workers the company would not have value so the idea that the workers and owners ought to be the same cohort has a great deal of attraction. Wealth creation is tied to ownership and the

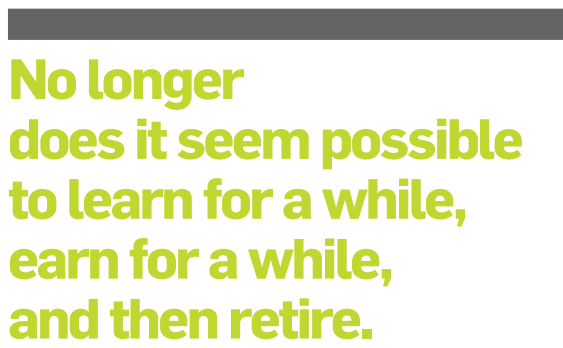

work that creates value. One can see the attraction of linking these together in the form of owner-workers.

Making people more valuable is also tied to the capacity to produce value. Increasing skills and knowledge increases the potential to do valuable work so education is part of the equation. We are seeing new forms of education emerging, partly through online access to information and partly as a consequence of longer lives and thus longer careers. No longer does it seem possible to learn for a while, earn for a while, and then retire. $\mathrm{Ca}$ reers may extend over periods of six decades or more during which time technology will have changed society and its needs dramatically. Continued learning will be needed during the course of a working career. Indeed, long-lived people may have multiple careers over time.

As we contemplate the future of work, it seems inescapable that technology will play a major role in increasing human ability to do work that is of value to the society. While there is a popular meme today that seeks to demonize automation and robotics, the alternative view is that these technologies will enhance our ability to do productive work. I see them as a means for augmenting our capacity to be productive and innovative, making each of us potentially more valuable to each other and our society.

Vinton G. Cerf is vice president and Chief Internet Evangelist at Google. He served as ACM president from 2012-2014.

Copyright held by author/owner. 